Marco Berti MD,

Guido Fanelli MD,

Andrea Casati MD,

Daniele Lugani $M D$,

Giorgio Aldegheri MD,

Giorgio Torri MD

\title{
Comparison between epidural infusion of fen- tanyl/bupivacaine and morphine/bupivacaine after orthopaedic surgery
}

Purpose: To compare epidural infusions of bupivacaine-fentanyl and bupivacaine-morphine mixtures for postoperative pain relief after total hip replacement.

Methods: In a prospective, randomized, double-blind study, 30 ASA physical status I-II patients undergoing total hip replacement were studied. Anaesthesia was provided by combined general/epidural anaesthesia without epidural opioids. Postoperative epidural analgesia was by continuous infusion of bupivacaine $0.125 \%\left(4 \mathrm{ml} \cdot \mathrm{hr} r^{-1}\right)$ with either $0.05 \mathrm{mg} \cdot \mathrm{ml}^{-1} \mathrm{mor}^{-}$

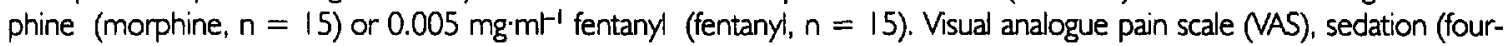
point scale), respiratory rate, pulse oximetry, rescue analgesics and supplemental oxygen were recorded by a blind observer at $1,3,6,9,12$ and $24 \mathrm{hr}$ after surgery.

Results: No differences in pain relief, sedation, or non-respiratory side effects were observed between the two groups. Rescue analgesics were required in three patients in the fentanyl group (20\%) and in two receiving morphine (13.3\%) (P:NS). Two patients in the fentanyl group and three in the morphine group required oxygen due to $\mathrm{SpO}_{2}<90 \%$ (P:NS). Both opioid/bupivacaine mixtures decreased haemoglobin oxygen saturation compared with preoperative values. The mean $\pm \mathrm{SD} \mathrm{SpO}_{2}$ values measured at $3,6,12$ and $24 \mathrm{hr}$ were $94.4 \pm 1,92.6 \pm 0.9,92 \pm 0.8$, and $92.8 \pm 1$ in the morphine group, $95.3 \pm 0.5,95 \pm 0.5,94.6 \pm 1.2$, and $95.6 \pm 1$ in the fentanyl group $(P<0.05)$.

Conclusion: Continuous epidural infusion of bupivacaine-morphine or bupivacaine-fentanyl mixtures provided similar pain relief. Patients receiving morphine showed a more marked decrease in $\mathrm{SpO}_{2}$ than those receiving fentanyl. However, the average $\mathrm{SpO}_{2}$ remained $>90 \%$ in both groups.

Objectif : Comparer des perfusions épidurales de mélanges de bupivacaïne-fentanyl et de bupivacaïne-morphine utilisés comme analgésique post opératoire à la suite de la mise en place d'une prothèse totale de la hanche.

Méthodes : Dans une étude prospective, randomisée et en double insu, on a étudié 30 patients ASA de condition phy sique I et II, devant subir la mise en place d'une prothèse totale de la hanche. On a procédé à une anesthésie générale combinée à une anesthésie épidurale sans opioïdes épiduraux. L'analgésie épidurale post opératoire consistait en une perfusion continue de bupivacaïne $0,125 \%\left(4 \mathrm{ml} \cdot \mathrm{hr}^{-1}\right)$ avec, soit $0,05 \mathrm{mg}^{-\mathrm{ml}^{-1}}$ de morphine (morphine, $\mathbf{n}=15$ ), soit 0,005 $\mathrm{mg} \cdot \mathrm{ml}^{-1}$ de fentanyl (fentanyl, $\mathrm{n}=15$ ). L'échelle visuelle analogique (EVA) de la douleur, la sédation (échelle en quatre points), la fréquence respiratoire, l'oxymétrie de pouls, les doses analgésiques de rattrapage et l'oxygène de supplément ont été enregistrés par un observateur aveugle à la répartition à $1,3,6,912$ et 24 heures après la chirurgie.

Résultats : Aucune différence dans l'analgésie, la sédation ou les effets secondaires non respiratoires n'a été observée entre les deux groupes. Des analgésiques de rattrapage ont été nécessaires pour trois patients dans le groupe qui avait reçu du fentanyl $(20 \%)$ et pour deux patients dans le groupe ayant reçu de la morphine $(13,3 \%)(P: N S)$. Deux patients dans le groupe fentanyl et trois dans le groupe morphine ont eu besoin d'oxygène à la suite d'une $\mathrm{SpO}_{2}<90 \%(P: N S)$. Les deux mélanges d'opioïde et de bupivacaïne diminuent la saturation en oxygène de l'hémoglobine par rapport aux valeurs pré opératoires. La moyenne \pm l'écart type des valeurs de la $\mathrm{SpO}_{2}$ mesurée à 3, 6, 12 et 24 heures ont été de $94,4 \pm 1 ; 92,6 \pm 0,9 ; 92 \pm 0,8$ et $92,8 \pm$ । dans le groupe morphine, $95,3 \pm 0,5 ; 95 \pm 0,5 ; 94,6 \pm 1,2$ et 95,6 \pm I dans le groupe fentanyl $(P<0,05)$.

Conclusion : Une perfusion épidurale continue du mélange de bupivacaïne-morphine ou du mélange de bupivacaine-fen tanyl fournit une analgésie semblable. Les patients qui ont reçu de la morphine ont montré une plus grande diminution de la $\mathrm{SpO}_{2}$ que ceux qui ont reçu du fentanyl. Toutefois, la moyenne de la $\mathrm{SpO}_{2}$ demeure $>90 \%$ dans les deux groupes.

From the Department of Anaesthesiology and Intensive Care - University of Milan, IRCCS H. San Raffaele, via Olgettina 60, 20132 Milan, Italy.

Address correspondence to: Dr. A. Casati, Phone: 39-2-26432656; Fax: 39-2-26412823; E- mail:casati.andrea@hsr.it

Accepted for publication March 2, 1998. 
$\mathrm{P}$ OSTOPERATIVE epidural analgesia by means of opioid and local anaesthetic mixtures is an effective method for the management of postoperative pain. Although contrasting results have been reported in humans studies, ${ }^{1-7}$ a synergistic effect between local anaesthetic and opioids has been demonstrated in animal models, in which the antinociceptive effects of opioid/local anaesthetic mixtures were greater than those of opioid or local anaesthetic alone. ${ }^{8}$ Since hydrophilic opioids, such as morphine, remain in the cerebrospinal fluid and may be responsible for undesirable side effects (e.g. delayed onset of peak analgesic effect and late respiratory depression), highly lipophilic opioids such as fentanyl have been used to reduce the side effects of extradural opioid administration..$^{8-10}$

The goal of the present investigation was to compare, in a double-blind study, the analgesic effect of postoperative epidural infusions of either bupivacainemorphine or bupivacaine-fentanyl mixtures after total hip replacement.

\section{Methods}

The study protocol was approved by Hospital Ethics Committee, and informed consent was obtained from each patient. Patients undergoing elective total hip replacement and having an epidural catheter as part of their anaesthetic technique participated in the study. Obese patients as well as patients with pulmonary, cardiac, renal, hepatic, cerebrovascular, or psychiatric disease were excluded from the study.

The day before surgery baseline peripheral haemoglobin oxygen saturation was measured with the patients spontaneously breathing room air (Oxypac Station, Dräger, Germany), and all patients were educated in the use of the $100 \mathrm{~mm}$ visual analogue pain scale (VAS).

After arrival in the operating theatre, patients received a standard intravenous infusion of $10 \mathrm{ml} \cdot \mathrm{kg}^{-1}$ Ringer's lactate solution, then an epidural catheter was inserted at the $\mathrm{L}_{3}-\mathrm{L}_{4}$ or $\mathrm{L}_{2}-\mathrm{L}_{3}$ interspace. After an epidural test dose (60 $\mathrm{mg}$ lidocaine $2 \%$ ) confirmed the correct catheter location, epidural block up to $T_{10}$ (loss of pinprick sensation) was induced by $10-12 \mathrm{ml}$ lidocaine $2 \%$. Before induction of general anaesthesia, all patients received $1 \mu \mathrm{g} \cdot \mathrm{kg}^{-1}$ fentanyl $i v$; then combined general (isoflurane ${ }_{\mathrm{ET}} 0.2-0.6 \%$ ) and epidural anaesthesia (continuous infusion $3.5 \mathrm{ml} \cdot \mathrm{hr}^{-1}$ bupivacaine $0.5 \%$ ) was provided. No epidural opioids were given until the start of postoperative epidural infusion. Standard ASA monitoring was used during surgery. Before the cement for the prosthesis had been applied, the lungs were ventilated with oxygen $100 \%$ and 5 $\mathrm{mg} \cdot \mathrm{kg}^{-1}$ hydrocortisone $i \nu$ were administered. Patients developing a sudden decrease in oxygen saturation and hypocapnia at the time of prosthesis cementation were excluded from the study.

Using sealed envelopes, patients were randomly allocated to two groups for the choice of epidural opioid. Patients in the morphine group $(\mathrm{n}=15)$ received 0.05 $\mathrm{mg} \cdot \mathrm{ml}^{-1}$ morphine in bupivacaine $0.125 \%$; patients in the fentanyl group $(\mathrm{n}=15)$ received $0.005 \mathrm{mg} \cdot \mathrm{ml}^{-1}$ fentanyl in bupivacaine $0.125 \%$. A continuous epidural infusion of the study solution was started immediately after surgery at a rate of $4 \mathrm{ml} \cdot \mathrm{hr}^{-1}$ after a $5 \mathrm{ml}$ bolus of the same solution. The mixture of local anaesthetic and opioid was injected into the epidural space by means of a syringe pump for $24 \mathrm{hr}$ after surgery. The infusion syringes were prepared in a double-blind fashion by one anaesthetist, who did not take any further part in the evaluation of patients. If the patients asked for more analgesia, or the visual pain scale was $>40 \mathrm{~mm}$ a non steroidal antiinflammatory drug was allowed as rescue analgesic (75 mg diclophenac iv). Postoperatively, patients remained in the recovery room for four hours, then they were transferred to the orthopaedic ward where standard thromboprophylactic therapy was started (5000 U heparin sc every $12 \mathrm{hr}$ ). Pulse oximetry was continuously recorded in all patients from the end of surgery to the end of the study (Oxypac Station, Dräger, Germany).

Non invasive arterial blood pressure, heart rate, respiratory rate and haemoglobin oxygen saturation were measured at $1,3,6,9,12$ and $24 \mathrm{hr}$ after the end of surgery. At the same time, the degree of sedation and pain relief was also evaluated. Sedation was evaluated according to a four-point scale ( 1 = awake and alert, 2 $=$ mildly sedated easy to wake up when spoken to, 3 = moderately sedated, easy to wake up when slightly shaken, $4=$ deeply sedated and difficult to wake up when shaken). Pain relief was assessed using a $100 \mathrm{~mm}$ visual analogue scale (VAS) with end points labelled "no pain" and "worst possible pain". At the occurrence of nausea $10 \mathrm{mg}$ metoclopramide iv was given and the need for antiemetic drug was recorded.

If oxygen saturation decreased to $<90 \%$ for more than one minute, supplemental oxygen by face mask was administered. Need for oxygen therapy during the postoperative period was recorded as a minor respiratory complication, and pulse oximetry values recorded during oxygen therapy were not considered for statistical analysis. A decrease of respiratory rate $<10 \mathrm{bpm}$ together with deep sedation was considered a major respiratory complication.

Both patients and anaesthetists caring for postoperative analgesia and recording measured parameters 
were blinded to the opioid administered.

Statistical analysis was performed using the statistical software package Statview 11 (Abacus Concepts, USA). Anthropometric comparisons were made using unpaired Student's test and Fisher exact test for ordinal data. Pain scores, oxygen saturation, as well as respiratory rate and haemodynamic parameters results were compared using two-factor ANOVA for repeated measures with Scheffe and Dunnett tests for multiple comparisons. Side-effects were compared with Fisher exact test. A value of $P<0.05$ was considered significant. Results are presented as mean \pm standard deviation (SD) for continuous variables and as median (range) for ordinal data.

\section{Results}

Anthropometric data of studied patients are summarized in Table I: no differences in age, weight, height, sex distribution and ASA physical status were observed between those patients receiving epidural morphinebupivacaine and those receiving fentanyl-bupivacaine.

Six patients in the morphine $(40 \%)$ and three in the fentanyl group $(20 \%)$ required antiemetic therapy ( $P$. NS).

There were no differences between either group in the degree of pain relief at any of the measurement times: mean pain scores during the study period ranged between $15 \mathrm{~mm}$ and $53 \mathrm{~mm}$ in the morphine group and between $11 \mathrm{~mm}$ and $58 \mathrm{~mm}$ in the fentanyl one (Figure 1). Two patients in the morphine group (13\%) and three in the fentanyl group (20\%) required rescue iv analgesia due to inadequate pain relief which produced clinical improvement.

No differences in haemodynamic parameters, respiratory rate or degree of sedation were observed at any measurement time between the two groups (Table II).

None of the patients developed major respiratory complications requiring naloxone. Three patients in the morphine group (20\%) and two in the fentanyl group (13\%) required oxygen by face mask due to a decrease in $\mathrm{SpO}_{2}<90 \%$ ( $P$ : NS). Patients requiring oxygen therapy were not different from others in terms of height, weight and age. One of them, receiving the morphine mixture, showed preoperative $\mathrm{SpO}_{2}$ of $94 \%$ while, in the others, baseline $\mathrm{SpO}_{2}$ ranged between $95 \%$ and $98 \%$. However, none of the patients showing at least one episode of mild hypoxia required more than a one hour of oxygen therapy. In both groups oxygen saturation was lower than baseline during the study period $(P<0.05)$. At $3,6,9,12$ and 24 hr $\mathrm{SpO}_{2}$ was lower in patients receiving morphinebupivacaine than in those receiving fentanyl-bupivacaine $(P<0.05)$ (Figure 2$)$.

\section{Discussion}

The present study demonstrated that continuous epidural infusion of low doses of either morphine or fentanyl in combination with bupivacaine $0.125 \%$ provided good postoperative analgesia after total hip replacement with no difference in pain relief or nonrespiratory side effects. Higher bupivacaine and lower opioid concentrations were used than in previous reports. ${ }^{5,6,10}$ However, the doses of morphine and fentanyl used were similar to those reported in other studies. ${ }^{11,12}$ Our results also suggested that, when using low doses of either morphine or fentanyl in combination with local anaesthetic solutions, the dose ratio of 10:1 between the two opioids provided similar analgesia and may be considered as the equianalgesic ratio.

Both morphine and fentanyl groups developed decreases of $\mathrm{SpO}_{2}$ during the study. Many surgeryrelated factors might have contributed to these results, and the present study shows the lack of a control group of patients receiving alternative analgesic methods, such as conventional parenteral opioid therapy. While differences in $\mathrm{SpO}_{2}$ were noted between the

TABLE I Anthropometric parameters of studied patients receiving continuous epidural infusion of morphine/bupivacaine (Morphine, $\mathrm{n}=15$ ) or fentanyl/bupivacaine (Fentanyl, $\mathrm{n}=15$ ) mixtures.

\begin{tabular}{lll}
\hline & Morphine & Fentanyl \\
& $(n=15)$ & $(n=15)$ \\
\hline Age $(\mathrm{yr})$ & $62.6 \pm 8.3$ & $64.1 \pm 7.1$ \\
Weight $(\mathrm{kg})$ & $72.6 \pm 16.4$ & $60.0 \pm 22.0$ \\
Height $(\mathrm{cm})$ & $164 \pm 10.5$ & $162 \pm 9.8$ \\
Male $/$ Female & $7 / 8$ & $8 / 7$ \\
ASA & II (I-II) & II (I-II) \\
\hline
\end{tabular}

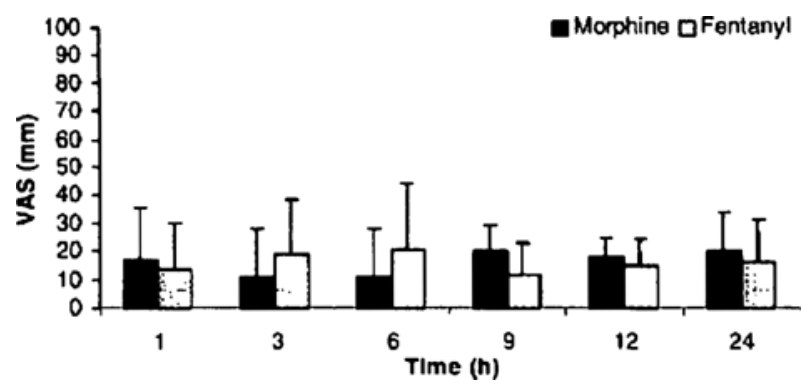

FIGURE 1 Mean ( \pm SD) pain scores on the $100 \mathrm{~mm}$ visual analogue scale (VAS) measured at 1, 3, 6, 9, 12 and 24 hours after the end of surgery in patients receiving continuous epidural infusion of morphine/bupivacaine (Morphine, $\mathrm{n}=15$ ) or fentanyl/bupivacaine (Fentanyl, $\mathrm{n}=15$ ) mixtures. 
TABLE II Descriptive statistics of mean arterial blood pressure (MAP), heart rate (HR), respiratory rate (RR) and sedation scores recorded at each of measurement times in patients receiving continuous epidural infusion of morphine/bupivacaine (Morphine, $n=15$ ) or fentanyl/bupivacaine (Fentanyl, $\mathrm{n}=15$ ) mixtures. [Sedation was assessed on a four-point scale: 1 = awake and alert, 2 = mildly sedated easy to wake up when spoken to, 3 = moderately sedated, easy to wake up when slightly shaken, $4=$ deeply sedated and difficult to wake up when shaken].

\begin{tabular}{|c|c|c|c|c|c|c|}
\hline & $I b r$ & $3 \mathrm{br}$ & $6 \mathrm{br}$ & $9 \mathrm{br}$ & $12 \mathrm{br}$ & $24 \mathrm{br}$ \\
\hline \multicolumn{7}{|c|}{ Morpbine $(n=15)$} \\
\hline MAP (mm Hg) & $83 \pm 7.6$ & $86 \pm 14$ & $77 \pm 10$ & $82 \pm 13$ & $84 \pm 13$ & $85 \pm 16$ \\
\hline $\mathrm{HR}(\mathrm{bpm})$ & $78 \pm 9.5$ & $78 \pm 15$ & $76 \pm 10$ & $82 \pm 12$ & $80 \pm 14$ & $80 \pm 16$ \\
\hline $\mathrm{RR}(\mathrm{bpm})$ & $15 \pm 3$ & $15.9 \pm 2.5$ & $15 \pm 2.1$ & $14 \pm 2.1$ & $15.6 \pm 2.3$ & $13 \pm 3$ \\
\hline Sedation scale & $2(1-2)$ & $1(1-2)$ & $1(1-2)$ & $1(1-3)$ & $1(1-3)$ & $1(1-2)$ \\
\hline \multicolumn{7}{|l|}{ Fentanyl $(\mathrm{n}=15)$} \\
\hline $\mathrm{MAP}(\mathrm{mm} \mathrm{Hg})$ & $79 \pm 7.5$ & $85 \pm 9.2$ & $82 \pm 9$ & $85 \pm 12$ & $84 \pm 10$ & $85 \pm 8.1$ \\
\hline HR (bpm) & $74 \pm 11$ & $84 \pm 15$ & $78 \pm 7$ & $79 \pm 7$ & $82 \pm 9$ & $79 \pm 10$ \\
\hline $\mathrm{RR}(\mathrm{bpm})$ & $16 \pm 4$ & $15.8 \pm 1.7$ & $16 \pm 1.6$ & $15 \pm 2.0$ & $14.2 \pm 2.5$ & $16.5 \pm 1.6$ \\
\hline Sedation scale & $1(1-2)$ & $1(1-2)$ & $1(1-1)$ & $1(1-2)$ & $1(1-3)$ & $1(1-1)$ \\
\hline
\end{tabular}

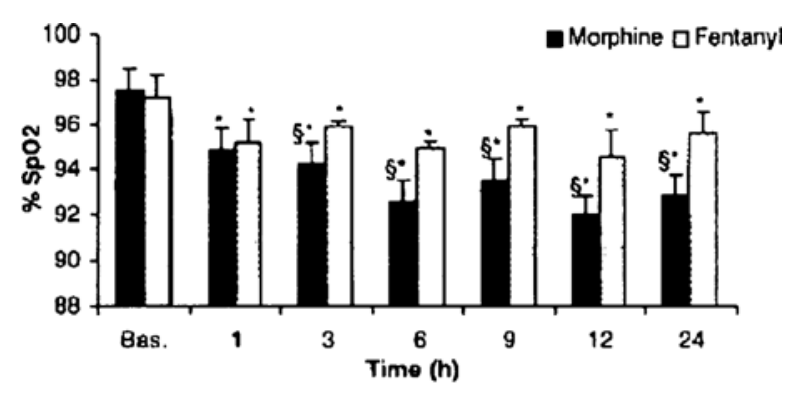

- $P<0,05$ vs Bas. § $P<0,05$ vs Fentanyl

FIGURE 2 Mean ( \pm SD) peripheral haemoglobin oxygen saturation (\% $\left.\mathrm{SpO}_{2}\right)$ measured preoperatively (Bas.) and at $1,3,6,9,12$ and 24 hours after the end of surgery in patients receiving continuous epidural infusion of morphine/bupivacaine (Morphine, $n=15$ ) or fentanyl/bupivacaine (Fentanyl, $n=15$ ) mixtures.

two groups, the clinical importance of this change might be questioned, since the average $\mathrm{SpO}_{2}$ in both groups remained at levels which might be typical for elderly patients undergoing major surgery. When using highly lipophilic fentanyl, the epidural fat probably acted as a drug reservoir minimizing the rostral spread of opioid molecules within the cerebro-spinal fluid.10 This would probably explain the lower effects on $\mathrm{SpO}_{2}$ observed in patients receiving the fentanylbupivacaine mixture than in those receiving the more hydrophilic morphine. ${ }^{13,14}$

Respiratory depression has been reported after epidural administration of either morphine or fentanyl; ${ }^{8,9,15}$ but severe respiratory depression during continuous epidural opioid infusion is rare, occurring in $<1 \%$ of patients receiving epidural opioids. ${ }^{16}$ It should be also considered that the combination of local anaesthetic and opioid allows further reduction in the daily dose of epidural opioid.

One further concern with the present study might be the choice of $\mathrm{SpO}_{2}$ values $<90 \%$ as the threshold for supplemental oxygen therapy. We considered mild hypoxia a minor respiratory complication. It has been demonstrated that postoperative episodic decreases of $\mathrm{SpO}_{2}<90 \%$ for more than one minute are likely to be hypoxic phenomenona. ${ }^{17,18}$

Previous studies reported higher incidences of undesired non-respiratory side effects in patients receiving epidural morphine compared with those receiving epidural fentanyl. ${ }^{10,12}$ Although, in the present study, the need for antiemetic drugs was $\mathbf{5 0 \% \text { less }}$ with epidural fentanyl than morphine, this did not reach statistical significance. Patients in our study received a non-abdominal surgical procedure, while other studies considered patients undergoing major abdominal surgery, which probably emphasized the opioid-related emetic effects.

Concerning epidural administration of opioid/local anaesthetic mixtures, while animal studies are uniform in finding analgesic potentiation when epidural or intrathecal opioid and local anaesthetic solutions are combined, ${ }^{8,19,20}$ clinical studies have produced conflicting results. Badner et al. ${ }^{5,6}$ reported no advantages to pain relief by adding bupivacaine $0,1 \%$ to fentanyl $0,001 \%$ for postoperative epidural analgesia. Others reported that low doses of epidural morphine and bupivacaine reduced pain more than morphine alone during mobilization and coughing, but not at rest; while Cullen et al. demonstrated that pain scores in patients receiving an epidural infusion of opioid-local anaesthetic mixture were superior to those of patients receiving bupivacaine alone. ${ }^{21}$

Although severe complications have been reported 
after the insertion of epidural catheters in patients receiving prophylactic anticoagulant therapy, ${ }^{22}$ the use of routine thromboprophylaxis prior to epidural anaesthesia was considered to be safe..$^{23,24}$ Nonetheless, routine postoperative epidural analgesia has its own risks and benefits. To perform a cost/benefit analysis, all anaesthesia-related benefits should be considered; but this is not easy because benefits are more difficult to value than costs. ${ }^{25}$ Minimizing or preventing side effects and risks are economic benefits which can be balanced against, or purchased by, costs, and it is known that regional anaesthesia (particularly epidural technique) leads to reductions in intraoperative and postoperative complications thus improving morbidity and mortality after major surgery. ${ }^{4,26-29}$ Studies with sufficient statistical power, including patients receiving postoperative analgesia by conventional parenteral opioid therapy, are necessary to evaluate the cost-benefit ratio of postoperative epidural analgesia after total hip replacement, especially in terms of postoperative morbidity and hospital stay. However, our results demonstrated that continuous epidural infusion of low doses of either morphine or fentanyl associated with bupivacaine provides effective postoperative analgesia, with clinically acceptable effects on haemoglobin oxygen saturation.

\section{References}

1 Dahl JB, Rosenberg J, Hansen BL, Hjortss N-C, KebletH. Differential analgesic effects of low-dose epidural morphine and morphine-bupivacaine at rest and during mobilization after major abdominal surgery. Anesth Analg 1992; 74: 362-5.

2 Hjortsø NC, Neumann P, Frøsig F, et al. A controlled study on the effect of epidural analgesia with local anaesthetics and morphine on morbidity after abdominal surgery. Acta Anaesthesiol Scand 1985; 29: 790-6.

3 Liu S, Catpenter RL, Neal JM. Epidural anesthesia and analgesia. Their role in postoperative outcome. Anesthesiology 1995; 82: 1474-506.

4 Hansdottir $V$, Bake $B$, Nordberg $G$. The analgesic efficacy and adverse effects of continuous epidural sufentanyl and bupivacaine infusion after thoracotomy. Anesth Analg 1996; 83: 394-400.

5 Badner NH, Reimer EJ, Komar WE, Moote CA. Lowdose bupivacaine does not improve postoperative epidural fentanyl analgesia in orthopedic patients. Anesth Analg 1991; 72: 337-41.

6 Badner NH, Komar WE. Bupivacaine 0,1\% does not improve postoperative epidural fentanyl analgesia after abdominal or thoracic surgery. Can J Anaesth 1992; 39: 330-6.
7 Sinatra $R S$, Sevarino $F B, C h u n g J H$, et al. Comparison of epidurally administered sufentanyl, morphine and sufentanyl-morphine combination for postoperative analgesia. Anesth Analg 1991; 72: 522-7.

8 Akerman B, Arweström E, Post C. Local anesthetics potentiate spinal morphine antinociception. Anesth Analg 1988; 67: 943-8.

9 Cousins MJ, Mather LE. Intrathecal and epidural administration of opioids. Anesthesiology 1984; 61: 276-310.

10 Fischer $R L$, Lubenow TR, Liceaga A, McCartby RJ, Ivankovich $A D$. Comparison of continuous epidural infusion of fentanyl-bupivacaine and morphine bupivacaine in management of postoperative pain. Anesth Analg 1988; 67: 559-63.

11 De Castro J, Meynadier J, Zenz M. Regional Opioid Analgesia. Dordrecht: Kluwer Academic Publishers, 1991: 198-200.

12 Saito $\Upsilon$, Uchida $H$, Kaneko $M$, Nakatani M, Kosaka $\Upsilon$. Comparison of continuous epidural infusion of morphine/bupivacaine with fentanyl/bupivacaine for postoperative pain relief. Acta Anaesthesiol Scand 1994; 38: 398-401.

13 Welchew EA, Thorton JA. Continuous thoracic epidural fentanyl. A comparison of epidural fentanyl with intramuscular papaveretum for postoperative pain. Anaesthesia 1982; 37: 309-16.

14 Benumof $J L$, Alfery $D D$. Anesthesia for thoracic surgery. In: Miller RD (Ed.). Anesthesia. New York: Churchill-Livingstone, 1990: 1517-603.

15 Brockway MS, Noble DW, Sharwood-Smith GH, McClure JH. Profound respiratory depression after extradural fentanyl. Br J Anaesth 1990; 64: 243-5.

16 Chaney $M A$. Side effects of intrathecal and epidural opioids. Can J Anaesth 1995; 42: 891-903.

17 Rheineck-Leyssius AT, Kalkman CJ. Influence of pulse oximeter lower alarm limit on the incidence of hypoxaemia in the recovery room. $\mathrm{Br} \mathrm{J}$ Anaesth 1997; 79: 460-4.

18 Stausholm K, Rosenberg-Adamsen S, Edvardsen L, Keblet $H$, Rosenberg $J$. Validation of pulse oximetry for monitoring of hypoxaemic episodes in the late postoperative period. Br J Anaesth 1997; 78: 86-7.

19 Maves TJ, Gebhart GF. Antinociceptive synergy between intrathecal morphine and lidocaine during visceral and somatic nociception in the rat. Anesthesiology 1992; 76: 91-9.

20 Penning JP, Yaksh TL. Interaction of intrathecal morphine with bupivacaine and lidocaine in the rat. Anesthesiology 1992; 77: 1186-200.

21 Cullen $M L$, Staren ED, El-Ganzouri A, Logas WG, Ivankovich $A D$, Economou SG. Continuous epidural infusion for analgesia after major abdominal operations: a randomized, prospective, double-blind study. Surgery 1985; 98: 718-28. 
22 Metzger $G$, Singbartl $G$. Spinal epidural hematoma following epidural anesthesia versus sponteneous spinal subdural hematoma. Two case reports. Acta Anaesthesiol Scand 1991; 35: 105-7.

23 Haljamäe $H$. Thromboprophylaxis, coagulation disorders, and regional anaesthesia. Acta Anaesthesiol Scand 1996; 40: 1024-40.

24 Allemann BH, Gerber H, Gruber UF. Perispinal anaesthesia and subcutaneous administration of low-dose heparin-dihydergot for prevention of thromboembolsm (German). Anaesthetist 1983; 32: 80-3.

25 Jobnstone RE, Martinec CL. Costs of anesthesia. Anesth Analg 1993; 76: 840-8.

26 Sharrock NE, Cazan MG, Hargett MJL, Williams-Russo $P$, Wilson $P D J r$. Changes in mortality after total hip and knee arthroplasty over a ten-year period. Anesth Analg 1995; 80: 242-8.

27 Scott NB, Keblet $H$. Regional anaesthesia and surgical morbidity. Br J Surg 1988; 75: 299-304.

28 Hole $A$, Terjesen $T$, Breivik $H$. Epidural versus general anaesthesia for total hip arthroplasty in elderly patients. Acta Anaesthesiol Scand 1980; 24: 279-87.

29 Liu SS, Carpenter RL, Mackey DC, et al. Effects of perioperative analgesic technique on rate of recovery after colon surgery. Anesthesiology 1995; 83: 757-65. 